\title{
PRODUTIVIDADE E ACÚMULO DE N EM CANA-DE-AÇÚCAR SOB SISTEMAS DE COLHEITA SEM QUEIMA
}

\section{PRODUCTIVIDAD Y ACUMULACIÓN DE NITRÓGENO ENSISTEMA DE COSECHA DE CAÑA DE AZÚCAR BAJO QUEMA}

\section{PRODUCTIVITY AND N ACCUMULATION IN SUGAR CANE UNDER BURNING HARVESTING SYSTEM}

\author{
Victor Vinicius Silva Barros ${ }^{1}$; José Mauro de Sousa Paiva ${ }^{2}$ \\ DOI: https://doi.org/10.31692/978-65-991061-4-9.157-162
}

\section{INTRODUÇÃO}

A cana-de-açúcar é uma planta perene que pertence à família das Poáceas, originaria do Sudeste Asiático, possui seu metabolismo fotossintético $\mathrm{C}_{4}$, pois possui alta capacidade fotossintética, com um alto acúmulo de massa seca tanto em sua parte área como na sua zona radicular, seguindo a sua fase final onde ocorre a maturação e um alto acumulo de sacarose nos seus colmos (RAMOS et al., 2009).

O Brasil é o maior produtor de cana-de-açúcar, sendo o terceiro em áreas plantadas, ficando atrás apenas de soja e milho, tendo em toda sua área territorial um clima favorável para seu cultivo, desde que o cultivo seja cultivares adaptadas, principalmente, ao clima, que geralmente é caracterizado por apresentar um elevado déficit hídrico anual, precipitações irregulares e a falta de instrução científica da cultura para a região cultivada.

O potencial de produção da cana-de-açúcar, é caracterizado por seus subprodutos açúcar, etanol e energia elétrica, entre outras, tanto na agricultura quanto na indústria, o que faz dessa cultura uma das mais importantes atividades da agroindústria nacional e mundial, já que sua atividade é responsável por geração de emprego (CORPERSUCAR, 2010). A produtividade dessa planta é regulada por diversos fatores de produção, dentre as quais se destacam: planta, solo, clima, práticas culturais, controle de pragas e doenças, colheita maturação e corte (ORLANDO FILHO et al., 1999). Sempre que possível devemos manejar os fatores de produção adequadamente e gerenciados pelo homem através de sistemas de planejamento, controle e execução, visando a maximização das produtividades econômicas. $\mathrm{O}$ objetivo final de uma exploração agrícola comercial é o lucro.

A fonte nitrogenada mais utilizada na cultura é a ureia, e quando aplicada sobre a palha, apresenta elevada perda de $\mathrm{N}-\mathrm{NH}_{3}$ por volatilização, o que pode afetar a absorção de $\mathrm{N}$

\footnotetext{
${ }^{1}$ Engenharia Agronômica, Instituto Federal de Educação Ciência e tecnologia do Piauí, vb40987@gmail.com

2 Engenheiro Agrônomo, Engenheiro agrônomo do SENAR, josemaurosp-10@ hotmail.com
} 
pela cultura (PRAMMANEE et al., 1989; DENMEAD et al., 1990; CANTARELLA et al., 1999). Dessa forma a produtividade agrícola no Brasil não se relacionam apenas a radiação solar, temperatura e água, e sim a disponibilidade de quantidades adequadas de nutrientes (CARMONA et al., 1990). O manejo inadequado de um canavial, especialmente a adubação nitrogenada, pode ter redução tanto na produção quanto na sua longevidade, dessa forma reduzindo, por conseguinte o número de colheitas ou cortes entre as reformas (BOLOGNA, 2007).

\section{FUNDAMENTAÇÃO TEÓRICA}

O Brasil é o maior produtor da cultura da cana-de-açúcar, com aproximadamente $33 \%$ de todo o montante produzido no mundo (JADOSKI ET al. 2010), essa liderança tem marcado a importância dessa cultura para a economia mundial, considerando o panorama de produtividade dos canaviais da região.

A deficiência de $\mathrm{N}$ nas plantas causa a redução da síntese de clorofila, de aminoácidos que são essenciais para a produção de carboidratos e esqueletos carbônicos (EPSTEIN e BLOOM, 2006). A adubação nitrogenada destaca-se como uma das práticas culturais mais estudadas em cana de açúcar, visto que todos os estudos sobre nitrogênio apresentam resultados variáveis e muitas vezes até contraditórios. A necessidade do N pela cana-deaçúcar é crucial no período de desenvolvimento da planta, que vai do período imediatamente após a germinação até o fechamento do canavial.

A resposta à fertilização nitrogenada reflete em maior vigor das soqueiras, tornando-se necessário manejar a cana-de-açúcar como uma cultura perene. Apesar da instabilidade climática em algumas regiões produtoras neste primeiro trimestre, como é o caso do Nordeste, a perspectiva é de crescimento de 5,9\% no rendimento da cultura, a produtividade média brasileira está estimada em $73.5 \mathrm{mil} \mathrm{kg/ha,} \mathrm{maior} \mathrm{que} \mathrm{a} \mathrm{safra} \mathrm{2012/13,} \mathrm{que} \mathrm{foi} \mathrm{de} 69 \mathrm{mil}$ kg/ha. (Conab 2013/2014).

A queimada da cana-de-açúcar é uma atividade tipicamente poluidora, que degrada o meio ambiente, afetando a saúde pública. Esta prática vem sendo questionada pela alta emissão de $\mathrm{CO}_{2}$ e gases de nitrogênio e enxofre que são responsáveis pelas chuvas ácidas, além de provocar perdas significativas de nutrientes para as plantas (BIO, 1999).

A obrigatoriedade de colheita da cana-de-açúcar sem queima da palhada aliada aos custos crescentes de produção torna imprescindível a adoção de novas tecnologias no manejo agrícola dessa cultura, como métodos de preparo do solo com menor mobilização do solo e consumo de combustível e no uso racional de fertilizantes (SOUZA et al., 2005; ROSSETTO 
et al. 2010).

\section{METODOLOGIA}

O experimento foi conduzido na Fazenda Várzea, no município Brejo - MA, Região

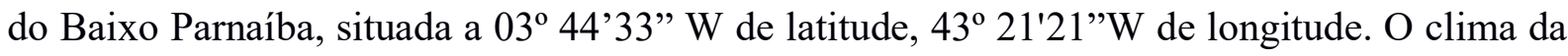
região corresponde na classificação de Koppen ao tipo Aw, caracterizado por chuvas no verão e seca no inverno. A temperatura média foi de $29^{\circ} \mathrm{C}$.

O experimento teve duração de dois anos em cana-soca $\left(2^{\circ}\right.$ e $3^{\circ}$ corte $)$ no período de 2011 e 2012. Nesse período, as médias das temperaturas máximas e mínimas foram respectivamente $28^{\circ} \mathrm{C}$ e $29^{\circ} \mathrm{C}$. Os dados de temperaturas e precipitações foram obtidos pelo Programa de Monitoramento Climático em Tempo Real da Região Nordeste (PROCLIMA), o solo e classificado como Latossolo Amarelo. O delineamento experimental utilizado foi de blocos ao acaso com três repetições, sendo os blocos separados por ruas de 2,0 m, e cada bloco foi composto por 3 parcelas, com um total do experimento foi de $7920 \mathrm{~m}^{2}$. Cada parcela foi subdividida em 6 (seis) parcelas e adubadas com diferentes doses de ureia, sendo elas, 60, 80, 100, 120 e $140 \mathrm{~kg} \mathrm{~N} \mathrm{ha}^{-1}$, e uma parcela testemunha, onde não foi adubada.

Para a variedade RB 863129 a dose de $100 \mathrm{~kg} \mathrm{~N}$ ha $^{-1}$ foi substituída por adubação com vinhoto, oriundo de destilaria da própria fazenda, com dose de $80 \mathrm{~m}^{3} \mathrm{ha}^{-1}$. Cada parcela experimental constituiu-se de sete linhas com 1 metro de espaçamento entre sulco e 18 metros de comprimento e 7 metros de largura, totalizando $126 \mathrm{~m}^{2}$ de área.

$\mathrm{Na}$ adubação, além do $\mathrm{N}$, foi aplicado potássio em todos os tratamentos, na dose de $140 \mathrm{~kg} \mathrm{ha}^{-1}$ de $\mathrm{K}_{2} \mathrm{O}$ (cloreto de potássio). As variedades utilizadas e estudada cana-de-açúcar, com 3 (três) variedades avaliadas, que são: RB 867515, RB 863129 e RB 92579.

Foram coletadas amostras no centro das parcelas, para evitar o efeito de bordadura. As amostras foram secas em estufa de aeração forçada, com temperatura de $60-65^{\circ} \mathrm{C}$, até massa constante. O material seco da fração da planta (colmo) foi moído com auxílio de um moinho forrageiro com peneira de $1 \mathrm{~mm}$. Depois, foram armazenadas em envelopes de papel e submetidas à digestão para determinação dos teores de $\mathrm{N}\left(\mathrm{g} \mathrm{ha}^{-1}\right)$, utilizando-se a metodologia proposta por Vaccaro et al. (2004).

O teor de Nitrogênio $(\mathrm{N})$ foi obtido por uma mistura digestora (sulfato de potássio + sulfato de cobre) e ácido sulfúrico, com digestão-destilação sulfúrica, utilizando-se o método semimicro Kjeldahl.

Os resultados obtidos foram submetidos à análise de variância e as médias comparadas entre si pelo teste $t$ de Student Para a análise estatística dos dados foi utilizado o programa 


\section{INFOSTAT.}

\section{RESULTADOS E DISCUSSÃO}

Pelos resultados da $1^{\mathrm{a}}$ soqueira a melhor resposta para adubação nitrogenada foi obtida

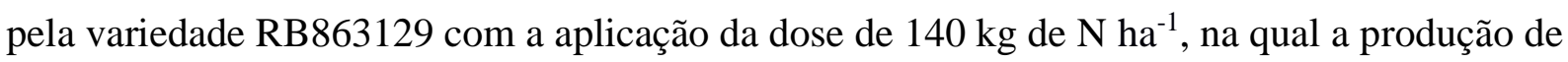
colmos em 63\% quando comparada com a testemunha. As doses 80 e $120 \mathrm{Kg} \mathrm{N} \mathrm{ha-1}$ incrementaram a produção em 47 e $46 \%$, em relação a testemunha. O tratamento onde o vinhoto aplicado obteve resultado semelhante a dose de $60 \mathrm{Kg} \mathrm{ha}^{-1}$ respectivamente.

Para a variedade RB867515, a maior produtividade de colmos foi obtida com a dose de $120 \mathrm{~kg}$ de $\mathrm{N} \mathrm{ha}^{-1}$ a produção de colmos em $46 \%$ quando comparado com a testemunha. A aplicação de $\mathrm{N}$ nas doses de 60,80 e $100 \mathrm{Kg} \mathrm{ha}^{-1}$ obtiveram resultados semelhantes na produtividade de colmos, sendo estas $82,44,80,78$ e 81,44 ton ha $^{-1}$ respectivamente. A produção de colmos para a dose de $140 \mathrm{~kg}$ de $\mathrm{N} \mathrm{ha}^{-1}$ não diferiu significativamente da testemunha.

Para a variedade RB92579, a maior produtividade em termos de peso fresco de colmos

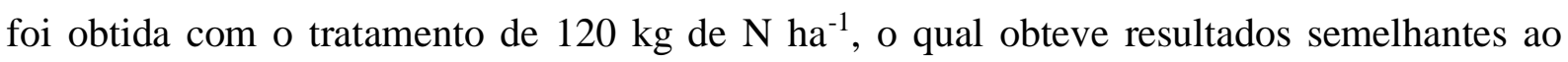
tratamento de $80 \mathrm{~kg} \mathrm{~N} \mathrm{ha}^{-1}$, sendo estes em média $23 \%$ superiores em relação a testemunha, o

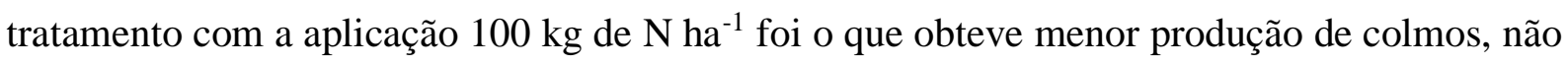
diferindo da testemunha $(\mathrm{P}>0,05)$. O efeito benéfico da aplicação de $\mathrm{N}$ corrobora os resultados obtidos por Orlando Filho et al. (1999).

Resultados semelhantes foram encontrados por Cardoso (2002) em cana-de açúcar, sem despalha a fogo, observou que a redução na aplicação de nitrogênio de 100 para $30 \mathrm{~kg} \mathrm{~N}$ $\mathrm{ha}^{-1}$ causou queda drástica no rendimento dos colmos.

Pelos resultados da $2^{\mathrm{a}}$ soqueira a variedade RB863129 os melhores resultados foram encontrados para os tratamentos com aplicação de 80 e novamente, como na primeira soca, com a dose de $140 \mathrm{Kg}$ de $\mathrm{N} \mathrm{ha}^{-1}$, os quais apresentaram o mesmo valor para produção de colmos, representando um incremento de $61 \%$ na produtividade quando comparados com a testemunha.

Assim como na $1^{\text {a }}$ soqueira, a variedade RB867515 apresentou melhor desempenho quando foi aplicada a dose de $120 \mathrm{Kg}$ de $\mathrm{N}$ ha-1, enquanto as doses de 60,80 e $100 \mathrm{Kg}$ de $\mathrm{N}$ $\mathrm{ha}^{-1}$ apresentaram produtividade de 82,4; 80,7; e 81,4 ton ha ${ }^{-1}$. E novamente, para dose de 140 $\mathrm{Kg}$ de $\mathrm{N} \mathrm{ha}^{-1}$ mesma tendência foi observada comparando-se com a $1^{\mathbf{a}}$ uma vez que essa não diferiu da testemunha com valores de produtividade de 65,73 e 68,1 e 65,7 ton ha${ }^{1}$ respectivamente. No entanto, comparando-se as testemunhas da $1^{\mathbf{a}}$ e $2^{\mathbf{a}}$ soca, observa-se que a 
produtividade se manteve constante.

A maior produtividade de colmos para a variedade RB92579 foi observada com a dose de $140 \mathrm{~kg} \mathrm{ha}^{-1}$ de $\mathrm{N}$, diferindo significativamente dos demais tratamentos, os quais apresentaram produtividade de 75,47,81,37, 108,93 e 102,57 ton ha ${ }^{-1}$ para as doses de 60, 80, 100 e $120 \mathrm{Kg} \mathrm{ha}^{-1}$ de $\mathrm{N}$ respectivamente. Com relação a testemunha, observou-se decréscimo de produtividade em $31 \%$ comparando-se com a $1^{\mathbf{a}}$ soca, indicando a importância do manejo da adubação nitrogenada ao longo dos ciclos, e ao que tudo indica em doses superiores a 120 kg N ha ${ }^{-1}$. Neste sentido, Faroni (2008) em experimento com cana-de-açúcar avaliando a resposta da cultura a aplicação de $\mathrm{N}\left(0-120 \mathrm{~kg} \mathrm{ha}^{-1}\right)$ em duas áreas distintas, também observou aumento de produtividade da cultura com a aplicação desse nutriente.

\section{CONCLUSÕES}

A variedade RB92579 apesentou a maior produtividade de colmos na primeira e na segunda soqueira de cana-de-açúcar. A melhor dose observada para essa variedade foi de 120 $\mathrm{ha}^{-1}$.

\section{REFERÊNCIAS}

BIO. Revista Brasileira de Saneamento e Meio Ambiente.n.10, p.42-45, abril/junho.1999.

BOLOGNA, I. R. Produtividade da cana-de-açúcar relacionada ao nitrogênio residual da adubação e do sistema radicular. Brasília: Pesq. agropec. bras, v.42, n.2, p.249-256, fev. 2007.

CANTARELLA, H. et al. Perdas de nitrogênio por volatilização da amônia e resposta da cana-de-açúcar à adubação nitrogenada, em sistema de colheita de cana sem queima prévia. In: CONGRESSO NACIONAL DA STAB, 7, Londrina,1999. Anais... Londrina: STAB, 1999. p.82-87.

CARDOSO, F.P. Plantio direto em cana-de-açúcar. Direto no Cerrado, Passo Fundo, v. 7, p. 4, 2002.

CARMONA G., CHRISTIANSON C.B., BYRNES B.H. Temperature and low concentration effects of the urease inhibitor N-n-butyl thiophosphoric triamide (NBPT) on ammonia volatilization from urea. Soil Biology \& Biochemistry. v. 7, p. 933-937, 1990.

COPERSUCAR. Dados de produtividade safra 2010. Disponível em www.Copersucar. Com.br. Acesso as 12:00 do dia 01 de dezembro de 2010.

DENMEAD, O.T. et al. Volatilization of ammonia from urea and ammonium sulfate applied to sugarcane trash in North Queensland. Proceedings of the Australian Society of. Sugar Cane Technology, v.12, p.72-78, 1990. 
EPSTEIN, E.; BLOOM, A. Nutrição mineral de plantas: princípios e perspectivas. 2. ed. Londrina: Planta, 2006. 402 p.

FARONI, C.E. Eficiência agronômica das adubações nitrogenadas de plantio e após o primeiro corte avaliada na primeira soca da cana-de-açúcar. 2008. 190f. Tese (Doutor em Solos e Nutrição de Plantas) - Escola Superior de Agricultura 'Luiz de Queiroz', Universidade de São Paulo, Piracicaba, 2008.

JADOSKI, C.J.; TOPPA, B.E.V.; JULIANETTI, A.; HULSBOF, T.; ONO, E.O.; RODRIGUES, J.D.; Fisiologia do desenvolvimento do estádio vegetativo da cana, Pesquisa aplicada e agrotecnologia, v3, n2 Mai-Ago 2010.

ORLANDO FILHO, J.; RODELLA, A.A.; BELTRAME, J.A.; LAVORENTI, N.A. Doses, fontes e formas de aplicação de nitrogênio em cana-de-açúcar. STAB. Açúcar, Álcool e Subprodutos, Piracicaba, v. 17, n.4, p.39-41, 1999.

PRAMMANEE, P.; SAFFIGNA, P.G. ; WOOD, A.W. Loss of nitrogen from urea and ammonium sulfate applied to sugar cane crop residues. In: AUSTRALIAN SOCIETY OF SUGARCANE TECHNOLOGISTS, 11., Mackay, 1989. Proceedings. Mackay: Watson Fergunson, 1989. p.76-84.

RAMOS et al., Guia da Cana-de-açúcar- Avanço cientifico beneficia o País, v. 01, n. 6, p.6-7, setembro de 2009.

ROSSETTO. R.; F. L. LANDELL, M. G. A. ; CANTARELLA, H.; TAVARES, S.; VITTI, A. C.; PERECIN, D.N and K fertilisation of sugarcane rations harvested Without burnig. In: INTERNATIONAL SOCIETY OF SUGAR CANE TECHNOLOGISTES CONGRESS, 27. 2010, Procedings... Veracruz, México: D. M. Horgarth, 2010. 1CD-ROM.

SOUZA, Z. M. de; PRADO, R de M.; PAIXÃO, A. C. S.; CESARIN, L. G. Sistemas de colheita e manejo da palhada da cana-de-açúcar. Pesquisa Agropecuária Brasileira, v. 40, n. 3, p. 271-278. Março, 2005. 